\title{
Sann-Joong-Kuey-Jian-Tang increases the protein expression of microtubule-associated protein II light chain 3 in human colon cancer colo 205 cells
}

\author{
CHUN-YUAN CHENG ${ }^{1,2}$, YI-HSIANG LIN ${ }^{3}$ and CHIN-CHENG SU ${ }^{3,4}$ \\ ${ }^{1}$ Institute of Medicine, Chung Shan Medical University, Taichung 40201; ${ }^{2}$ Changhua Christian Hospital, Changhua 500; \\ ${ }^{3}$ Institute of Pharmacology and Toxicology, Tzu-Chi University; ${ }^{4}$ Division of General Surgery, \\ Buddhist Tzu-Chi General Hospital, Hualien 970, Taiwan, R.O.C.
}

Received April 10, 2009; Accepted June 22, 2009

DOI: $10.3892 / \mathrm{mmr} 00000160$

\begin{abstract}
Sann-Joong-Kuey-Jian-Tang (SJKJT), a traditional Chinese medicine, has been prescribed as complementary medication for colon cancer in Taiwan. However, its molecular mechanisms are not yet understood. In the present study, we investigated the effects of SJKJT on human colon cancer colo 205 cells in vitro. The cytotoxicity of SJKJT in colo 205 cells was evaluated using the MTT assay, and the protein expression of microtubule-associated protein II light chain 3 (MAP-LC3-II) was measured using Western blot analysis. The results showed that SJKJT inhibited the survival rates of colo 205 cells in a time- and dose-dependent manner, with an $\mathrm{IC}_{50}$ concentration at $24 \mathrm{~h}$ of $590.34 \mu \mathrm{g} / \mathrm{ml}$. In addition, SJKJT up-regulated the protein expression of MAP-LC3-II in colo 205 cells. These findings indicate that one of the molecular mechanisms by which SJKJT inhibits the proliferation of colo 205 cells in vitro may be through the induction of the autophagic pathway. SJKJT may therefore have therapeutic potential for the treatment of human colon cancer.
\end{abstract}

\section{Introduction}

Colon cancer is the second leading cause of cancer-related death in Western societies, and is ranked third as the cause of cancer-related death in Taiwan (1-3).

Autophagy is an alternative non-apoptotic route of programmed cell death (4). Autophagic targets have been proposed as novel approaches in anticancer therapy (5). The family of microtubule-associated protein light chain 3 (MAP-LC3)

Correspondence to: Dr Chin-Cheng Su, Division of General Surgery, Buddhist Tzu Chi General Hospital, No. 707, Sec. 3, Chung Yang Road, Hualien 970, Taiwan, R.O.C.

E-mail: succ.maeva@msa.hinet.net

Key words: Sann-Joong-Kuey-Jian-Tang, microtubule-associated protein II light chain 3, colo 205 cells, autophagy consists of MAP-LC3-I (18 kDa) and MAP-LC3-II (16 kDa). MAP-LC3-I is located in the cytoplasm, while MAP-LC3-II is a membrane-bound protein that is attached to an autophagosome. It is well documented that the autophagosome-associated protein MAP-LC3-II can be used as a marker of autophagy. The induction and inhibition of autophagy can be monitored by measuring total and free MAP-LC3-II levels using Western blotting. (6-8).

Traditional Chinese medicine is a well-known medical practice in Asia (9). Sann-Joong-Kuey-Jian-Tang (SJKJT), a traditional Chinese medicine, has been prescribed to treat tumors with lymph node invasion and inflammation. In this study, we evaluated the cytotoxicity and molecular mechanisms of SJKJT in human colon cancer colo 205 cells in vitro.

\section{Materials and methods}

Chemicals and reagents. Fetal bovine serum (FBS), sodium pyruvate, HEPES, dimethyl sulfoxide (DMSO), RPMI1640, MTT and the antibodies to $\beta$-actin and MAP-LC3-II were obtained from Sigma-Aldrich (St. Louis, MO, USA). Penicillin-streptomycin, trypsin-EDTA and glutamine were obtained from Gibco BRL (Grand Island, NY, USA). SDSPAGE running buffer 10X, Tris, Tween-20, SDS and 5X TBE buffer were obtained from Amresco (St. Louis, MO, USA). BioMax Flim was obtained from Kodak.

Sann-Joong-Kuey-Jian-Tang. SJKJT consists of 17 species of medicinal herbs including Coptis chinensis Franch, Cimicifuga heracleifolia Komar, Scutellaria baicalensis Georgi, Gentiana scabra Bunge, Trichosanthes cucumeroides Maxim, Phellodendron amurense Rupr, Anemarrhena asphodeloides Bunge, Platycodon grandiflour, Laminaria japonica Aresch, Bupleurum chinese DC, Glycyrrhiza uralensis Fisch, Sparganium stoloniferum Bucch, Curcuma aeruginosa Roxb, Forsythia suspense Vahl, Pueraria lobata Ohwi, Paeonia lactiflora Pall and Angelica sinensis Diels (10). The crude extract of SJKJT was obtained from Chuang Song Zong Pharmaceutical Co., Ltd. (Ligang Plant, Taiwan). 
Cell culture. Human colon cancer colo 205 cells were obtained from the Food Industry Research and Development Institute (Hsinchu, Taiwan). The cell lines were grown in RPMI-1640 supplemented with $2 \mathrm{mM}$ L-glutamine adjusted to contain $10 \mathrm{mM}$ HEPES, $1.0 \mathrm{mM}$ sodium pyruvate, $1 \%$ penicillinstreptomycin solution and $10 \%$ heat-inactivated FBS in a humidified incubator $\left(37^{\circ} \mathrm{C}, 5 \% \mathrm{CO}_{2}\right)$. Data presented in this study were from at least three independent experiments.

Cell proliferation assay. The colo 205 cells were plated in 6 -well plates at a density of $1 \times 10^{5}$ cells/well, and were allowed to adhere and grow for $24 \mathrm{~h}$. The medium was then replaced with $2 \mathrm{ml} /$ well of fresh medium, and various concentrations of SJKJT were added. Cells were allowed to grow for $24 \mathrm{~h}$. Subsequently, $200 \mu \mathrm{l}$ of 3-(4,5-dimethylthiazol-2-yl)-2,5-diphenyl-2H-tetrazolium bromide (MTT) was added, and cells were incubated at $37^{\circ} \mathrm{C}$ in the dark for $2 \mathrm{~h}$. The medium was removed and $1 \mathrm{ml}$ DMSO was added to the wells. Absorbance was measured using an ELISA plate reader at $590 \mathrm{~nm}$. Data were calculated as the percentage of proliferation using the following formula: Proliferation $(\%)=\left(\mathrm{OD}_{\text {test }}-\mathrm{OD}_{\text {blank }}\right) \times 100$, where $\mathrm{OD}_{\text {test }}$ and $\mathrm{OD}_{\text {blank }}$ are the optical density of the test substances and blank without cells, respectively.

Morphological changes. Colo 205 cells were seeded into 6-well culture plates (with RPMI-1640 containing 10\% FBS) and treated with various concentrations of SJKJT (0, $150,300,600$ and $1200 \mu \mathrm{g} / \mathrm{ml}$ ) or starvation medium (free of serum and amino acid) for $24 \mathrm{~h}$. Cellular morphological changes were observed by light microscopy (Leica, Nussloch, Germany).

Western blot assay. To detect the protein expression of MAPLC3-II by Western blotting, Colo 205 cells (5x 10\%/10-cm dish) were cultured overnight in medium. The medium was then removed, and cells were treated with various concentrations of SJKJT $(0,150,300$ and $600 \mu \mathrm{g} / \mathrm{ml})$ or starvation medium (free of serum and amino acid) for different time periods $(0$, 6, 12 and $24 \mathrm{~h}$ ) before being harvested by centrifugation. The MAP-LC3-II protein was extracted and examined by sodium dodecyl sulfate polyacrylamide gel electrophoresis (SDS-PAGE) and Western blotting as described previously (11). For protein extraction, cells were washed twice with ice-cold 1X PBS and lysed with a protein lysis buffer (ProPrep $\left.^{\mathrm{TM}}\right)$. After centrifugation, the supernatant was transferred to new tubes. Protein concentration was determined using the Bio-Rad protein assay. Total whole cell lysates $(50 \mathrm{mg})$ were separated on SDS-PAGE and transferred to PDVF membranes (Millipore, Billerica, MA, USA). The membranes were then incubated in blocking solution of 5\% non-fat milk in PBS (1X Dulbecco's phosphate-buffered saline) followed by overnight incubation with the appropriate primary antibodies. After complete washing with PBS-T (1X Dulbecco's phosphate-buffered saline and $0.1 \%$ Triton X-100) and incubation with horseradish peroxidase-conjugated secondary antibodies (Sigma-Aldrich) for $1 \mathrm{~h}$, immunocomplexes were developed with an enhanced horseradish peroxidase/luminal chemiluminescence reagent (Millipore) according to the manufacturer's instructions. Primary antibodies included a mouse monoclonal anti- $\beta$-actin antibody (1:5000 dilution) and a rabbit monoclonal MAP-LC3B antibody (1:1000 dilution) (Sigma-Aldrich).

Statistical analysis. The Student's t-test was used to analyze the statistical significance between SJKJT and the control groups. A p-value $<0.05$ was considered significant for all tests.

\section{Results}

Cytotoxicity of Sann-Joong-Kuey-Jian-Tang in colo 205 cells. The colo 205 cells were treated with various concentrations of $\operatorname{SJKJT}(0,150,300,600$ and $1200 \mu \mathrm{g} / \mathrm{ml})$ for $24 \mathrm{~h}$. Cells were examined under a contrast phase microscope (x50) and photographed (Fig. 1A). The colo 205 cells $\left(1 \times 10^{5}\right.$ cells/well; 6-well plates) were plated in RPMI-1640 medium containing $10 \%$ FBS with various concentrations of SJKJT $(0,150,300$, 600 and $1200 \mu \mathrm{g} / \mathrm{ml}$ ) for $24 \mathrm{~h}$, and the percentage of viable cells was determined using the MTT assay. At concentrations of SJKJT of 150, 300, 600 and $1200 \mu \mathrm{g} / \mathrm{ml}$, the percentages of viable cells relative to the control were $97.61 \pm 2.96$, $92.39 \pm 3.04,48.6 \pm 0.8$ and $40.8 \pm 8.75 \%$, respectively. The $\mathrm{IC}_{50}$ was $590.36 \pm 5.37 \mu \mathrm{g} / \mathrm{ml}$, and the proliferation rate was $<40 \%$ relative to control group when cells were treated with $1200 \mu \mathrm{g} / \mathrm{ml} \mathrm{SJKJT} \mathrm{for} 24 \mathrm{~h}$ (Fig. 1B). The results indicated that the cytotoxicity of SJKJT in colo 205 cells was dosedependent.

Morphological changes in the colo 205 cells. When colo 205 cells were treated with $600 \mu \mathrm{g} / \mathrm{ml} \mathrm{SJKJT}$ and serum-free medium for $24 \mathrm{~h}$, upon light microscopy, marked morphological changes were noted as compared to the control and serum-free group. Colo 205 cells treated with SJKJT presented a vacuolated cytoplasm, and the serum-free group exhibited an identical morphology (Fig. 2).

Sann-Joong-Kuey-Jian-Tang induces autophagy in colo 205 cells. The autophagic assay was confirmed by Western blotting. Colo 205 cells were treated with SJKJT $(600 \mu \mathrm{g} / \mathrm{ml})$ or serum-free medium for $24 \mathrm{~h}$. The protein expression of MAPLC3-II was increased compared to the control group (Fig. 3). To investigate the autophagic marker, the protein expression of MAP-LC3, colo 205 cells were treated with varying concentrations of $\operatorname{SJKJT}(0,150,300$ and $600 \mu \mathrm{g} / \mathrm{ml})$ for $24 \mathrm{~h}$, then treated with $600 \mu \mathrm{g} / \mathrm{ml} \mathrm{SJKJT}$ for different time periods $(0$, 6, 12 and $24 \mathrm{~h}$ ). The protein expression of MAP-LC3-II was analyzed using Western blot analysis. The results showed that MAP-LC3-II protein expression was up-regulated compared with the control group (Fig. 4A and B).

The percentage of autophagic cells in colo 205 cells treated with SJKJT. We examined the percentage of autophagic cells in colo 205 cells treated with SJKJT $(600 \mu \mathrm{g} / \mathrm{ml})$ for different time periods. The results showed that the colo 205 cells increased in volume after $6 \mathrm{~h}$. The percentage of colo 205 cells with vacuoles in the cytoplasm was $13.91 \pm 6.54$ after $12 \mathrm{~h}$. The cytoplasm of the colo 205 cells treated with SJKJT had clear vacuoles and exhibited a change in swelling after $48 \mathrm{~h}$ (Fig. 5A and B). 
A.

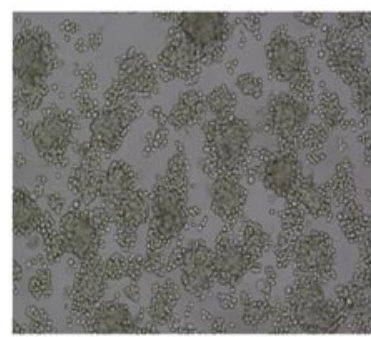

Control

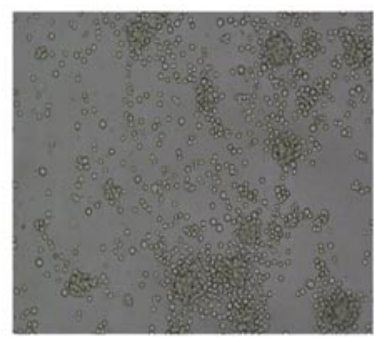

$150 \mu \mathrm{g} / \mathrm{ml}$

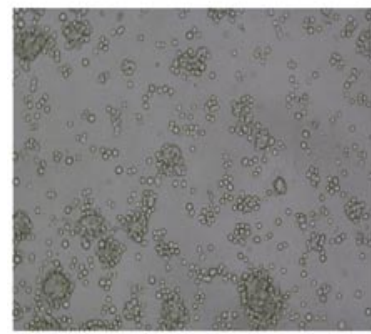

$300 \mu \mathrm{g} / \mathrm{ml}$

B.
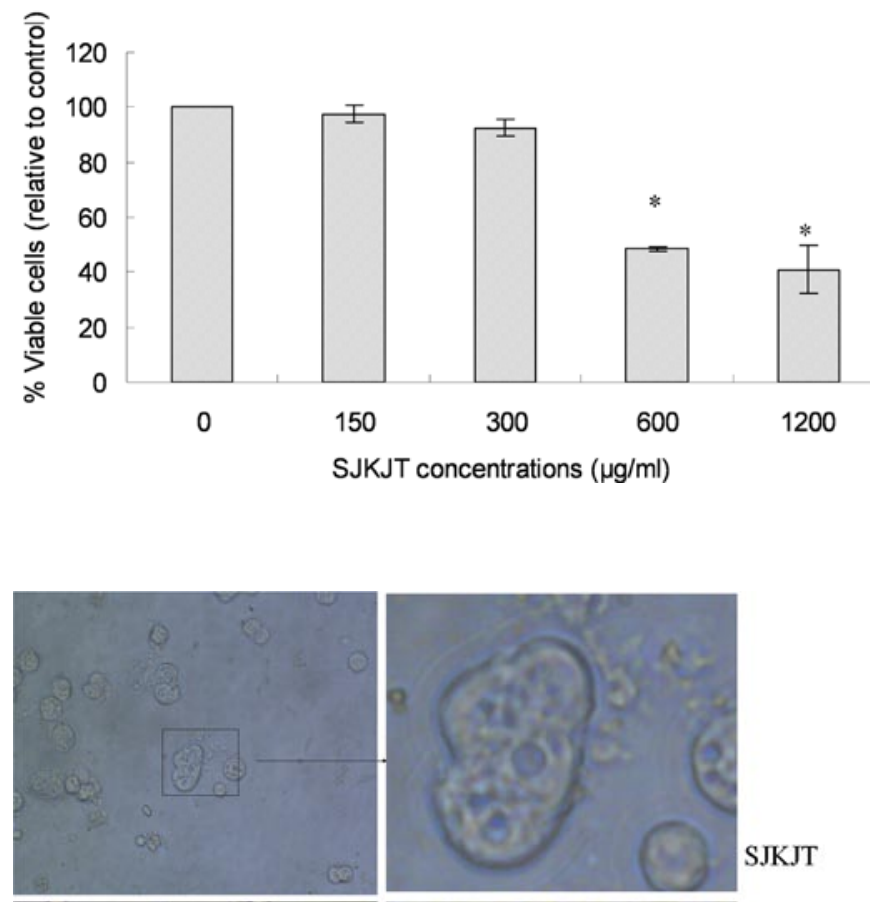

SJKJT
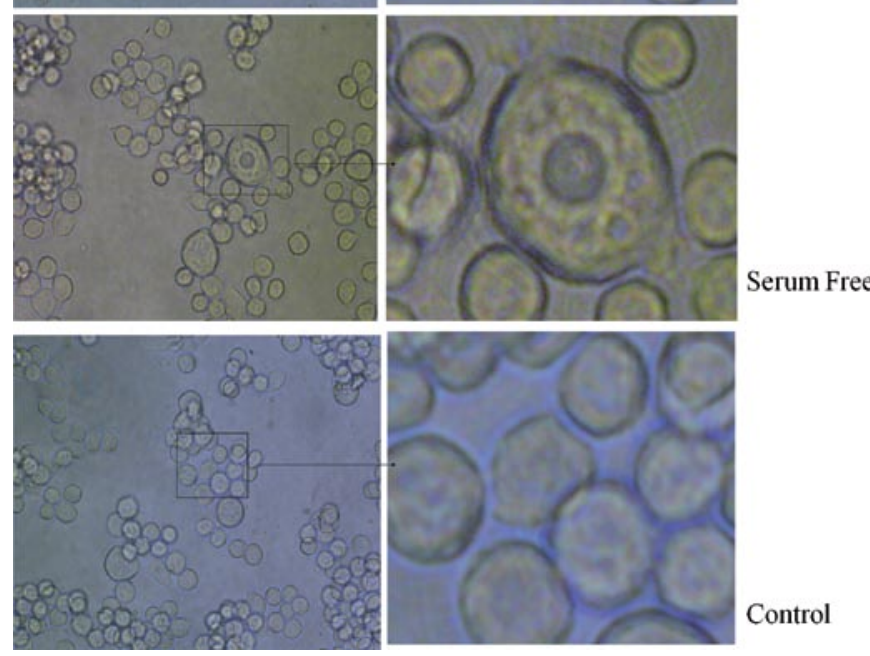

Control

Figure 2. Vacuolation of the cytoplasm at $24 \mathrm{~h}$ after serum-free and SJKJT treatment, observed at $\mathrm{x} 400$ by light microscopy.
Figure 1. (A) Colo 205 cells treated with various concentrations of SJKJT (0, $150,300,600$ and $1200 \mu \mathrm{g} / \mathrm{ml}$ ) for $24 \mathrm{~h}$. Cells were examined under a phase contrast microscope (x50) and photographed. (B) Colo 205 cells $\left(1 \times 10^{5}\right.$ cells/ well) treated with various concentrations of SJKJT $(0,150,300,600$ and $1200 \mu \mathrm{g} / \mathrm{ml}$ ) for $24 \mathrm{~h}$. The percentage of viable cells was determined using the MTT assay as described in Materials and methods. The results revealed that the cytotoxicity of SJKJT in colo 205 cells was dose-dependent. Each point is the mean \pm SD of three experiments. ${ }^{*} \mathrm{P}<0.05$.
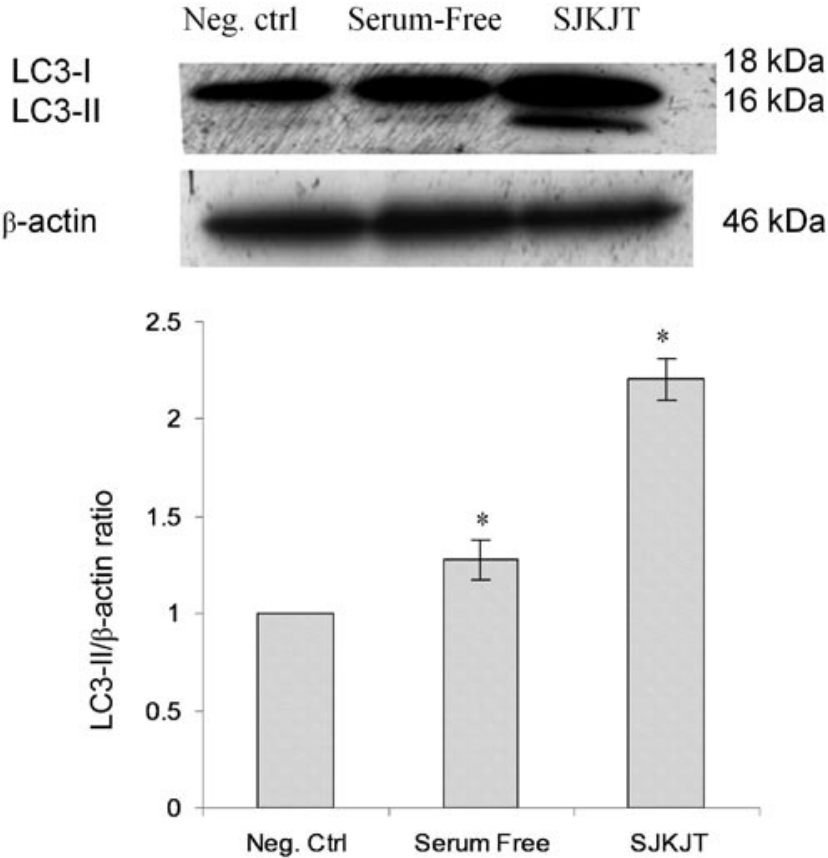

Figure 3. Colo 205 cells treated with SJKJT ( $600 \mu \mathrm{g} / \mathrm{ml}$ ) or serum-free medium for $24 \mathrm{~h}$. The protein expression of MAP-LC3-II was increased compared to the control group. Each point is the mean \pm SD of three experiments. ${ }^{*} \mathrm{P}<0.05$. 
A.
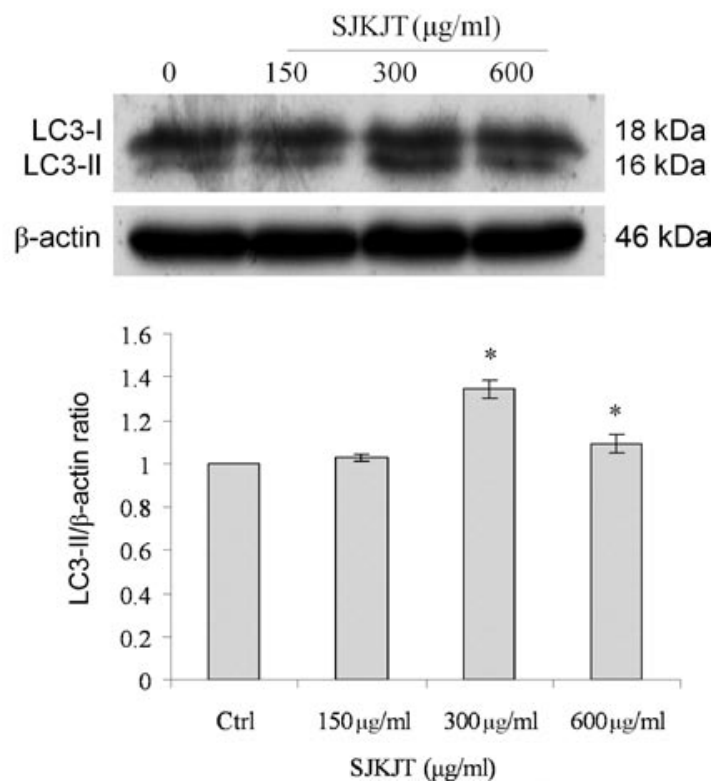

B.
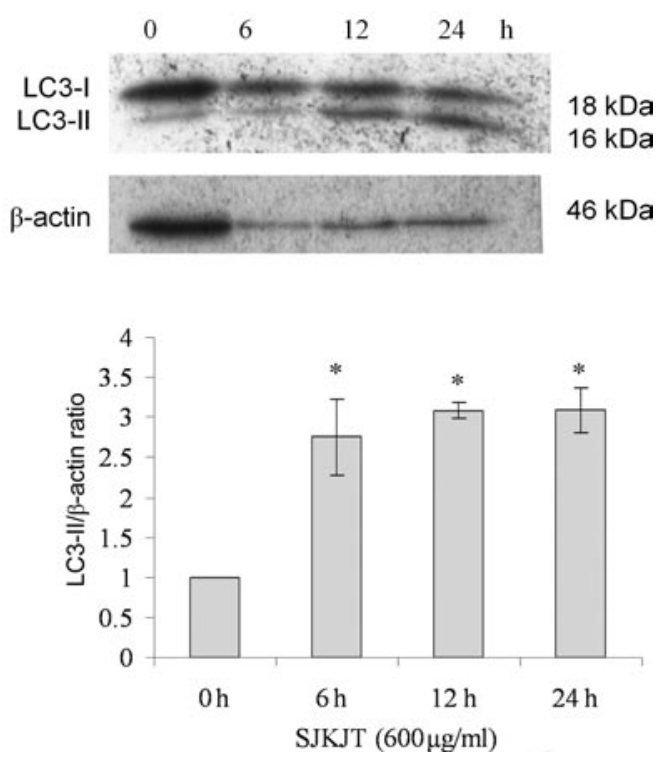

Figure 4. (A) Colo 205 cells treated with various concentrations of $\operatorname{SJKJT}(0,150,300$ and $600 \mu \mathrm{g} / \mathrm{ml})$ for $24 \mathrm{~h}$. Protein expression of MAP-LC3-II was analyzed using Western blotting. The results showed that MAP-LC3-II protein expression was up-regulated. Each point is the mean \pm SD of three experiments. "P<0.05. (B) Colo 205 cells were treated with SJKJT $(600 \mu \mathrm{g} / \mathrm{ml})$ for different time periods $(0,6,12$ and $24 \mathrm{~h})$. Protein expression of MAP-LC3-II was analyzed using Western blotting. The result showed that MAP-LC3-II protein expression was up-regulated. Each point is the mean \pm SD of three experiments. "P $<0.05$.

A.

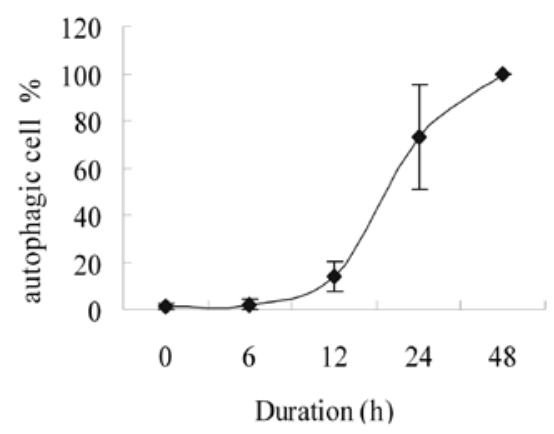

B.

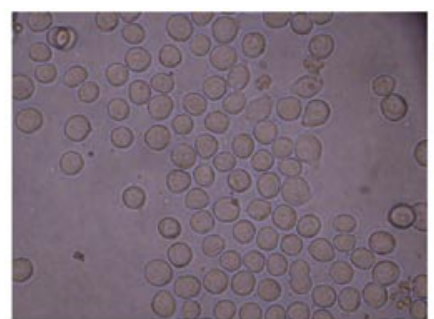

$0 \mathrm{~h}(1.24 \pm 1.41 \%)$

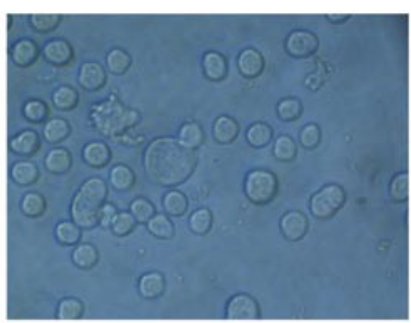

$6 \mathrm{~h}(2.20 \pm 1.96 \%)$

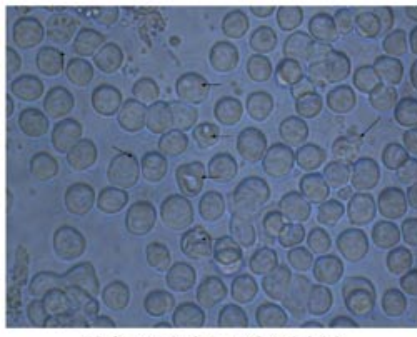

12 h $(13.91 \pm 6.54 \%)$

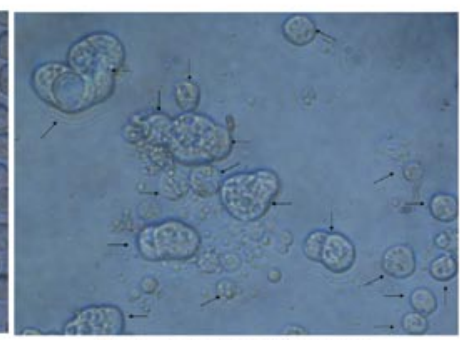

24 h $(73.05 \pm 22.51 \%)$

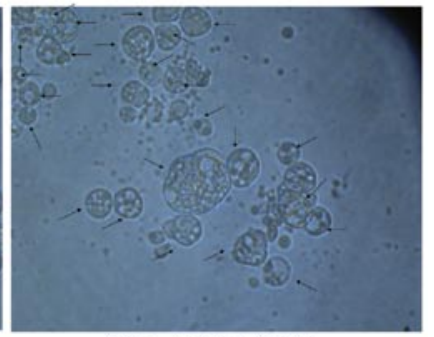

48 h $(100 \pm 0 \%)$

Figure 5. (A) The percentage of autophagic cells in colo 205 cells treated with $600 \mu \mathrm{g} / \mathrm{ml} \mathrm{SJKJT}$ for different time periods $(6,12,24$ and $48 \mathrm{~h})$ assessed by light microscopy (x400). The results showed that the colo 205 cells increased in volume after $6 \mathrm{~h}$. (B) Autophagic cells in colo 205 cells treated with $600 \mu \mathrm{g} /$ $\mathrm{ml}$ SJKJT for different time periods $(6,12,24$ and $48 \mathrm{~h}$ ) were observed by light microscopy (x400). The results showed that the cytoplasm of the colo 205 cells treated with SJKJT had clear vacuoles and exhibited a change in swelling after $48 \mathrm{~h}$. 


\section{Discussion}

Sann-Joong-Kuey-Jian-Tang does not demonstrate significant toxicity in certain types of normal cells. This may be related to differences between the genomic stability of cancer and normal cells $(10,12)$. In the present study, the results showed that SJKJT inhibited the proliferative rates of colo 205 cells in vitro in a dose-dependent manner.

Autophagosome-associated protein microtubule-associated protein light chain 3 (MAP-LC3) has been used as a marker of autophagy (13). Protein expression of LC3-type II can be detected using Western blot analysis. It is well documented that incubation in starvation medium (free of serum and amino acids) for $24 \mathrm{~h}$ induces autophagy $(14,15)$. In our study, serum and amino acid-free medium (serum-free group) was used to induce autophagy as a positive control. The results showed that treatment with both SJKJT and starvation medium induced morphological changes in the cytoplasm of colo 205 cells, but not in the control group. In addition, SJKJT treatment increased the protein expression of MAP-LC3-II in a timeand dose-dependent manner. Protein expression of LC3-II in colo 205 cells treated with SJKJT was up-regulated compared with the serum-free and control groups. Colo 205 cells were treated with $600 \mu \mathrm{g} / \mathrm{ml} \mathrm{SJKJT} \mathrm{for} \mathrm{0,} \mathrm{6,} \mathrm{12,} 24$ and $48 \mathrm{~h}$, and were observed using light microscopy. After $12 \mathrm{~h}$, vacuoles were detected in a high power field (x400). Morphological changes and the results of the Western blot analysis were in agreement. One of the molecular mechanisms responsible for the inhibition of proliferation of human colon cancer colo 205 cells by SJKJT in vitro may be the up-regulation of the protein expression of MAP-LC3-II to induce autophagy.

\section{Acknowledgements}

This study was supported by grant no. TCRD97-05 from the Research Section of Buddhist Tzu Chi General Hospital, Hualien, Taiwan. This study was supported in part by the Chen-Han Foundation for Education.

\section{References}

1. Jemal A, Tiwari RC, Murray T, et al: Cancer statistics, 2004. CA Cancer J Clin 54: 8-29, 2004.

2. Wei SC, Su YN, Tsai-Wu JJ, et al: Genetic analysis of the APC gene in Taiwanese familial adenomatous polyposis. J Biomed Sci 11: 260-265, 2004.

3. Statistics of Causes of Death, 2007. Department of Health, Executive Yuan, Taipei, Taiwan R.O.C., p33, 2008.

4. Clarke PG: Developmental cell death: morphological diversity and multiple mechanisms. Anat Embryol 181: 195-213, 1990.

5. Moretti Lu, Yang ES, Kim KW and Lu Bo: Autophagy signaling in cancer and its potential as novel target to improve anticancer therapy. Drug Resist Updat 10: 135-143, 2007.

6. Konado Ya and Kondo Se: Autophagy and cancer therapy. Autophagy 2: 85-90, 2006.

7. Kabeya Y, Mizushima N, Ueno T, et al: LC3, a mammalian homologue of yeast Apg8p, is localized in autophagosome membranes after processing. EMBO J 19: 5720-5728, 2000.

8. Yang YP, Liang ZQ, Gu ZL and Qin ZH: Molecular mechanism and regulation of autophagy. Acta Pharmacol Sin 26: 1421-1434, 2005.

9. Rauh R, Kahl S, Boechzelt H, Bauer R, Kaina B and Efferth T: Molecular biology of cantharidin in cancer cells. Chin Med 2: 8, 2007.

10. Hsu YL, Yen MH, Kuo PL, et al: San-Zhong-Kui-Jian-Tang, a traditional Chinese medicine prescription, inhibits the proliferation of human breast cancer cells by blocking cell cycle progression and inducing apoptosis. Biol Pharm Bull 29: 2388-2394, 2006.

11. Su CC and Lin YH: Tanshinone IIA inhibits human breast cancer cells through increased Bax to Bcl-xL ratios. Int J Mol Med. 22: 357-361, 2008.

12. Yang $\mathrm{CH}$ and Craise LM: Development of human epithelial cell systems for radiation risk assessment. Adv Space Res 14: 115-120, 1994.

13. Kirkegaard K, Taylor MP and Jackson WT: Cellular autophagy: Surrender, avoidance and subversion by microorganisms. Nat Rev Microbiol 2: 301-314, 2004.

14. Eskelinen EL, Prescott AR, Cooper J, et al: Inhibition of autophagy in mitotic animal cells. Traffic 3: 878-893, 2002.

15. Eskelinen EL, Illert AL, Tanaka Y, et al: Role of LAMP-2 in lysosome biogenesis and autophagy. Mol Biol Cell 13: 3355-3368, 2002. 